\title{
Prospective relations between Helicobacter pylori infection, coronary heart disease, and stroke in middle aged men
}

\author{
Peter H Whincup, Michael A Mendall, Ivan J Perry, David P Strachan, Mary Walker
}

\begin{abstract}
Objective-To determine whether Helicobacter pylori, a chronic bacterial infection often acquired in childhood, is associated with increased risk of coronary heart disease and stroke later in life. Design-Nested case-control study.

Setting-Prospective study of cardiovascular disease in men aged 40-59 years at entry (1978-1980) in 24 British towns.

Subjects-135 cases of myocardial infarction and 137 cases of stroke occurring before December 1991; 136 controls were identified, frequency matched to cases by town and age group.

Methods-Serum samples stored at entry were analysed by an enzyme linked immunosorbent assay for the presence of $H$ pylori specific IgG antibodies.
\end{abstract}

Results-95 of the myocardial infarction cases $(70 \%)$ and $93(68 \%)$ of the stroke cases were seropositive for $H$ pylori compared with $78(57 \%)$ of the controls (odds ratio for myocardial infarction $1.77,95 \%$ confidence interval (CI) 1.06 to $2.95, P=$ 0.03 ; odds ratio for stroke $1.57,95 \%$ CI 0.95 to $2.60, P=0.07)$. Helicobacter pylori infection was associated with manual social class, residence in Northern England or Scotland, cigarette smoking, higher systolic pressure and blood glucose, and a lower height-standardised forced expiratory volume in one second. Adjustment for these factors attenuated the relation between $H$ pylori and myocardial infarction (odds ratio $=1 \cdot 31$, $95 \% \mathrm{CI} 0.70$ to $2 \cdot 43, \mathrm{P}=0.40$ ) and effectively abolished the relation with stroke (odds ratio $=0.96,0.46$ to $2.02, P=$ $0.92)$. The relation between helicobacter infection and fatal myocardial infarction was slightly stronger (odds ratio $2 \cdot 41,95 \%$ CI 1.13 to $5 \cdot 12$ ) but was also markedly attenuated after adjustment $(1 \cdot 56,95 \% \mathrm{CI}$ 0.68 to $3 \cdot 61$ ).

Conclusion-In this prospective study the association between Helicobacter pylori infection and increased risk of myocardial infarction and stroke was substantially confounded by the relation between this infection, adult social class, and major cardiovascular risk factors.

(Heart 1996;75:568-572)

Keywords: coronary heart disease; Helicobacter pylori; stroke
Factors acting early in life may influence adult risk of coronary heart disease,,$^{12}$ and play a part in determining its social class distribution. ${ }^{3}$ Helicobacter pylori ( $H$ pylori) is a chronic bacterial infection which is usually acquired in childhood, particularly in socially deprived circumstances. ${ }^{45}$ Its associations with peptic ulcer disease and gastric cancer are well recognised $^{6-8}$; both of these conditions are associated with coronary heart disease.$^{910} \mathrm{~A}$ recent case-control study based on prevalent coronary heart disease in middle aged men provided some support for the possibility of an association between $H$ pylori and coronary heart disease. ${ }^{11}$ However, selection biases could not be excluded in that study, and only limited information was available on potential confounding factors. The problems of selection bias were addressed in a further crosssectional study in south London men, which found a strong relation between $H$ pylori seropositivity and electrocardiographic abnormalities suggestive of myocardial ischaemia or infarction, independent of a wide range of confounding variables. ${ }^{12}$ However, no study has yet prospectively investigated the relation between $H$ pylori infection and coronary heart disease. We have used a nested case-control study based on a longitudinal study of cardiovascular disease in middle aged men to examine the relation between $H$ pylori seropositivity and subsequent coronary heart disease and stroke. The relations between $H$ pylori and a range of cardiovascular risk factors have also been examined.

\section{Subjects and methods}

BRITISH REGIONAL HEART STUDY

The British Regional Heart Study is a longitudinal study of cardiovascular disease in $\mathbf{7 7 3 5}$ middle aged men aged 40-59 years (response rate $78 \%$ ) randomly selected from the age-sex registers of representative group general practices in each of 24 towns across England, Wales, and Scotland. The criteria for selecting the towns, the general practices, and the subjects, as well as the methods of data collection, have been presented in detail elsewhere. ${ }^{13-16} \mathrm{At}$ entry to the study in 1978-1980, a nurse administered a questionnaire to each man on occupation, smoking habits, alcohol intake, and medical history, including a modified WHO (Rose) chest pain questionnaire. ${ }^{17}$ Social class was based on the longest-held occupation, using the Registrar General's 1971 classification and including a separate 
category for armed forces. Cigarette smoking was classified into six groups, current smokers (1-19, 20, 21-39, 40+/day), ex-smokers, and never smokers. Alcohol intake was classified into five groups: none, occasional $(<1$ unit/week), light (1-15 units/week), moderate (16-42 units/week), heavy ( $>42$ units/week).

Body mass index (weight/height ${ }^{2}$ ) was used as an index of relative weight. Blood pressure was measured twice using a London School of Hygiene sphygmomanometer with the subject seated. The mean of the two readings was used in the analysis; all blood pressure readings were adjusted for observer variation within each town. Forced expiratory volume was measured twice with the subject seated using a Vitalograph spirometer (model J49B2); data are based on the maximum value and have been standardised for height. ${ }^{18}$ An orthogonal three-lead electrocardiogram was recorded, ${ }^{19}$ from which heart rate was derived. A non-fasting blood sample was collected for laboratory analysis; in the last 18 towns serum was stored at $-20^{\circ} \mathrm{C}$ for later analyses. Preexisting coronary heart disease is based on the presence of one of the following: definite angina, possible or definite myocardial infarction on Rose questionnaire; recall of a previous doctor diagnosis of angina or myocardial infarction; and electrocardiographic evidence of possible or definite myocardial ischaemia or infarction. ${ }^{14}$ Pre-existing stroke and diabetes are based on recall of a previous doctor diagnosis of the respective diagnoses.

All men have been followed up for all-cause mortality and for cardiovascular morbidity, with a follow up loss of less than $1 \%$ to date. Fatal cases of ischaemic heart disease and stroke were ascertained through the National Health Service Central Registers in Southport (England) and Edinburgh (Scotland) on the basis of a death certificate with ICD-9 codes $410-414$ or ICD-9 codes $430-438$ respectively. Ascertainment of non-fatal cardiovascular events was based on reports from general practitioners, supplemented by regular reviews of general practice records. Non-fatal myocardial infarction was diagnosed in accordance with World Health Organisation criteria ${ }^{16}$; non-fatal stroke included all cases with a reported neurological deficit lasting more than 24 hours and of presumed vascular origin. Death occurring within 28 days of the onset of symptoms led to reclassification as a fatal episode.

\section{CASE-CONTROL STUDY DESIGN}

The case-control study was based on first major cardiovascular events, fatal and nonfatal, occurring between the beginning of follow up and December 1991, but was restricted to subjects in 18 of the 24 study towns ( $n=$ 5661) for whom stored serum samples were available. The study was designed to be of sufficient size to detect a twofold increase in the odds of first myocardial infarction or stroke associated with $H$ pylori infection with $80 \%$ power at $\mathrm{P}=0.05$, assuming a seropositivity rate of $40 \%$ in the control group. ${ }^{11}$ Cases included were a random one-third sample of first myocardial infarctions and all cases of first stroke identified during follow up. Subjects with pre-existing disease were not excluded, but the influence of these subjects has been specifically examined in the analysis. Controls were subjects who survived to the end of the study period free from incident myocardial infarction and stroke. They were frequency matched to cases by town and by age group (in five year age bands).

\section{LABORATORY METHODS}

$H$ pylori specific IgG antibody titres were measured in duplicate in the stored serum samples between August and October 1994 by an inhouse enzyme linked immunosorbent assay (ELISA) and a partially purified antigen as described elsewhere. ${ }^{4}$ Titres were dichotomised into seropositive and seronegative values using a cutoff value of 0.824 optical density units, defined in an endoscopy population to be $98 \%$ sensitive and $94 \%$ specific for the presence of infection in endoscopic biopsy samples. ${ }^{4}$ The validity of the measurements obtained in serum stored for 14-16 years was supported by the observation that $H$ pylori seropositivity rates were higher in subjects reporting the presence of overcrowding and the absence of a bathroom and hot water supply in the childhood home. This is consistent with earlier reports. ${ }^{4}$ Moreover, the relation between $H$ pylori and gastric cancer has previously been demonstrated using serum samples up to 13 years old. ${ }^{7}$ Measurement of total serum cholesterol and of HDL cholesterol, carried out at the time of the original survey measurements, has been described in detail elsewhere. ${ }^{20}$

\section{STATISTICAL ANALYSIS}

Statistical analyses were carried out using the SAS statistical package. ${ }^{21}$ Frequencies were compared by $\chi^{2}$ tests. Standard linear regression techniques using PROC GLM were used to obtain age-adjusted mean values. Adjusted odds ratios were obtained using logistic regression. Age, systolic pressure, blood glucose, forced expiratory volume in $1 \mathrm{~s}\left(\mathrm{FEV}_{1}\right)$, and cholesterol were fitted as continuous variables (fitting each at five levels made no difference to the analysis). Smoking (six levels), alcohol intake (five levels), social class (seven levels), and town (18 levels) were fitted using dummy variables. Where appropriate, three geographical regions (Southern England, Northern England and Scotland) were defined; Southern and Northern England were separated by a line joining the Wash and the Bristol Channel.

\section{Results}

There were 135 cases of myocardial infarction, of which $54(40 \%)$ were fatal, and 137 strokes, of which $29(21 \%)$ were fatal, and 136 controls. Ninety-five of the myocardial infarct cases $(70 \%)$ and $93(68 \%)$ of the stroke cases were seropositive for $H$ pylori compared with $78(57 \%)$ of the controls. The unadjusted odds ratio for myocardial infarction was 1.77 
Table 1 Cardiovascular risk factors in myocardial infarction and stroke cases

\begin{tabular}{|c|c|c|c|}
\hline isk factor & Myocardial infarction & Stroke & Controls \\
\hline 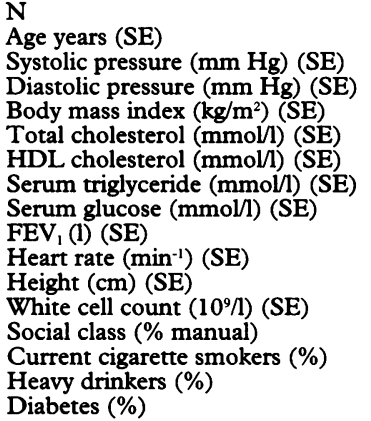 & $\begin{array}{l}135 \\
53 \cdot 8(0 \cdot 4) \\
152 \cdot 5(1 \cdot 7)^{\star \star \star} \\
85 \cdot 7(1 \cdot 1)^{\star \star} \\
26 \cdot 5(0 \cdot 3)^{\star \star \star} \\
6 \cdot 6(0 \cdot 1) \\
1 \cdot 07(0 \cdot 02)^{\star \star \star} \\
2 \cdot 25(0 \cdot 11)^{\star} \\
5 \cdot 92(0 \cdot 13)^{\star} \\
3 \cdot 14(0 \cdot 05)^{\star} \\
73 \cdot 4(1 \cdot 0) \\
171 \cdot 6(0 \cdot 1) \\
7 \cdot 44(0 \cdot 15)^{\star \star} \\
82 / 128(64)^{\star} \\
65 / 135(48)^{\star} \\
7 / 135(5)^{\star} \\
6 / 135(4)^{\star}\end{array}$ & $\begin{array}{l}137 \\
54 \cdot 0(0 \cdot 4) \\
163 \cdot 5(1 \cdot 9)^{\star \star \star} \\
88 \cdot 9(1 \cdot 1)^{\star \star \star} \\
25 \cdot 7(0.3) \\
6 \cdot 3(0 \cdot 1) \\
1 \cdot 12(0 \cdot 02) \\
2 \cdot 07(0 \cdot 10) \\
5 \cdot 99(0 \cdot 14)^{\star} \\
3 \cdot 00(0 \cdot 05)^{\star \star \star} \\
73 \cdot 0(1 \cdot 1) \\
172 \cdot 0(0 \cdot 1) \\
7 \cdot 65(0 \cdot 14)^{\star \star} \\
96 / 136(71)^{\star} \\
82 / 137(69)^{\star \star \star} \\
22 / 137(16)^{\star} \\
5 / 137(4)\end{array}$ & $\begin{array}{l}136 \\
53 \cdot 5(0 \cdot 4) \\
141 \cdot 5(1 \cdot 7) \\
80 \cdot 6(1 \cdot 1) \\
25 \cdot 2(0 \cdot 3) \\
6 \cdot 4(0 \cdot 1) \\
1 \cdot 20(0 \cdot 02) \\
1 \cdot 86(0 \cdot 10) \\
5 \cdot 46(0 \cdot 14) \\
3 \cdot 35(0 \cdot 05) \\
70 \cdot 5(1 \cdot 1) \\
172 \cdot 2(0 \cdot 1) \\
6 \cdot 79(0 \cdot 15) \\
74 / 134(55) \\
47 / 135(35) \\
7 / 135(5) \\
0 / 136(0)\end{array}$ \\
\hline
\end{tabular}

All mean values are adjusted for age. $\star \mathrm{P}<0.05, \star \star P<0.005, \star \star \star \mathrm{P}<0.0005$ for differences between cases and controls. Subjects whose longest-held occupation was in the armed force are excluded from the social class analysis. Data on smoking and drinking were not available for two control subjects.

(95\% CI 1.06 to $2.95, \mathrm{P}=0.03)$; that for stroke was $1.57(95 \%$ CI 0.95 to $2.60, \mathrm{P}=$ $0 \cdot 07)$. Other characteristics of the cases and controls are shown in table 1 . Mean blood pressures (systolic and diastolic), blood glucose, and white cell count and the prevalence of current smoking and diabetes were significantly higher both in myocardial infarction and in stroke cases when compared with controls; mean $\mathrm{FEV}_{1}$ values were significantly lower. Statistically significant differences in mean body mass index, HDL cholesterol, and triglyceride between myocardial infarction cases and controls were also observed. The proportion of subjects in manual occupations was higher in both myocardial infarction and stroke cases than in controls, although the difference was only statistically significant for stroke.

The relations between $H$ pylori seropositivity and cardiovascular risk factors were examined in the control population (table 2). $H$ pylori infection was associated with a higher prevalence of current smoking, with manual social class, and with residence in Scotland and Northern England. Mean values for sys-

Table 2 Helicobacter pylori and cardiovascular risk factors in controls

\begin{tabular}{|c|c|c|c|}
\hline & \multicolumn{2}{|c|}{ Helicobacter pylori status } & \multirow[b]{2}{*}{$P$ value } \\
\hline & Positive & Negative & \\
\hline $\mathbf{N}$ & 78 & 58 & \\
\hline Age (yr) (SE) & $53.8(0.5)$ & $53 \cdot 1(0 \cdot 6)$ & $0 \cdot 18$ \\
\hline $\mathrm{SBP}(\mathrm{mm} \mathrm{Hg})(\mathrm{SE})$ & $143.7(1.9)$ & $138 \cdot 3(2 \cdot 2)$ & 0.06 \\
\hline DBP (mm Hg) (SE) & $81.5(1.5)$ & $79 \cdot 5(1 \cdot 7)$ & $0 \cdot 37$ \\
\hline Body mass index $\left(\mathrm{kg} / \mathrm{m}^{2}\right)(\mathrm{SE})$ & $25 \cdot 2(0 \cdot 3)$ & $25 \cdot 2(0 \cdot 4)$ & 0.99 \\
\hline Total cholesterol (mmol/1) (SE) & $6 \cdot 32(0 \cdot 12)$ & $6 \cdot 55(0 \cdot 14)$ & $0 \cdot 23$ \\
\hline HDL cholesterol (mmol/l) (SE) & $1.22(0.03)$ & $1.17(0.03)$ & $0 \cdot 36$ \\
\hline Triglyceride $(\mathrm{mmol} / \mathrm{l})(\mathrm{SE})$ & $1 \cdot 82(0 \cdot 15)$ & $1.93(0 \cdot 17)$ & $0 \cdot 63$ \\
\hline Glucose (mmol/l) (SE) & $5 \cdot 66(0 \cdot 10)$ & $5 \cdot 20(0 \cdot 12)$ & 0.006 \\
\hline $\mathrm{FEV}_{1}$ (l) (SE) & $3.21(0.07)$ & $3.56(0.08)$ & 0.0008 \\
\hline Heart rate $\left(\min ^{-1}\right)(S E)$ & $71 \cdot 1(1 \cdot 3)$ & $69 \cdot 6(1.5)$ & 0.49 \\
\hline Height $(\mathrm{cm})$ (SE) & $172 \cdot 6(0 \cdot 75)$ & $171 \cdot 8(0.88)$ & 0.47 \\
\hline White cell count $\left(10^{\circ} / 1\right)(\mathrm{SE})$ & $6 \cdot 89(0 \cdot 18)$ & $6 \cdot 68(0 \cdot 20)$ & 0.45 \\
\hline Social class ( $\%$ manual) & $49 / 76(64)$ & $25 / 58(43)$ & 0.03 \\
\hline Current cigarette smokers (\%) & $33 / 77(43)$ & $14 / 58(24)$ & 0.04 \\
\hline Heavy drinkers (\%) & $5 / 77(6)$ & $2 / 58$ (3) & $0 \cdot 35$ \\
\hline Diabetes (\%) & $0 / 78(0)$ & $0 / 58(0)$ & - \\
\hline \multicolumn{4}{|l|}{ Region (\%): } \\
\hline $\begin{array}{l}\text { Southern England } \\
\text { Northern England }\end{array}$ & $21 / 78(27)$ & $24 / 58(41)$ & \\
\hline $\begin{array}{l}\text { Northern Eng } \\
\text { Scotland }\end{array}$ & $\begin{array}{l}37 / 78(47) \\
20 / 78(26)\end{array}$ & $\begin{array}{l}29 / 58(50) \\
5 / 58(9)\end{array}$ & 0.03 \\
\hline
\end{tabular}

Values are mean (SE) or proportion (\%). All mean values are adjusted for age. Subjects whose longest held occupation was in the armed forces are excluded from the social class analysis. Data on smoking and drinking not available for two control subjects. tolic blood pressure and serum glucose were higher in seropositive subjects, whereas $\mathrm{FEV}_{1}$ values were lower. There were no important differences in body mass index, total or HDL cholesterol concentrations, height, white cell count, or heart rate. The relation between $H$ pylori seropositivity and current smoking was slightly attenuated by adjustment for social class (adjusted odds ratio $2.08, P=0.07$ ). However, the differences in blood pressure, blood glucose, and $\mathrm{FEV}_{1}$ were little affected by adjustment either for social class or for town.

Table 3 shows the effects of adjustment for age, cardiovascular risk factors, and adult social class on the relations between $H$ pylori infection and risk of myocardial infarction and stroke. To correct for minor imbalances in the distribution of cases and controls between towns, these analyses have been standardised for town throughout. In the case of myocardial infarction, about one third of the increase in risk associated with $H$ pylori seropositivity was removed after adjustment for social class and a slightly larger proportion after adjustment for the cardiovascular risk factors most strongly related to $H$ pylori seropositivity (cigarette smoking, systolic pressure, blood glucose, $\mathrm{FEV}_{1}$ ). Neither of these adjusted odds ratios was statistically significant. Simultaneous adjustment for both groups of factors reduced the increased risk by more than a half. Additional adjustment for total and HDL cholesterol, triglyceride, heart rate, alcohol intake, and pre-existing diabetes had no effect on the results. The relation between $H$ pylori and stroke was markedly attenuated by adjustment for adult social class, with a corresponding loss of statistical significance. After adjustment for cardiovascular risk factors, the odds ratio for stroke was close to unity. There was no evidence of interaction between $H$ pylori and any of the individual cardiovascular risk factors examined, either for stroke or for myocardial infarction.

The relation between $H$ pylori seropositivity and coronary heart disease was examined after excluding men with pre-existing coronary heart disease (60 cases, five controls). While the age-adjusted odds ratio is only slightly lower than that for all men $(1.69,95 \%$ CI 0.92 to $3 \cdot 10, P=0.09$ ), the odds ratio adjusted for risk factors and social class is close to unity $(1.04,95 \%$ CI 0.50 to $2 \cdot 16, P=0.91)$. The relation between $H$ pylori and stroke is little affected by the exclusion of men with preexisting coronary heart disease and stroke (60 cases, five controls; data not presented). We also examined the relation between $H$ pylori seropositivity and coronary heart disease separately in men with fatal and non-fatal events. The odds ratios for fatal coronary heart disease were somewhat stronger than those for non-fatal coronary heart disease, both after age adjustment (OR [fatal] $2 \cdot 41,95 \%$ CI $1 \cdot 13$ to $5 \cdot 12$; OR [non-fatal] $1 \cdot 42,95 \%$ CI 0.79 to 2.54) and after adjustment for social class and risk factors (OR [fatal] $1.56,95 \% \mathrm{CI} 0.68$ to 3.61; OR [non-fatal] $1.02,95 \%$ CI 0.53 to $1.96)$. However, the differences in odds ratios between fatal and non-fatal outcomes were not 
Table 3 Odds ratios for Helicobacter pylori seropositivity with myocardial infarction and stroke

\begin{tabular}{|c|c|c|c|c|}
\hline \multirow[b]{2}{*}{ Adjustment } & \multirow[b]{2}{*}{ Odds ratio } & \multicolumn{2}{|c|}{ Myocardial infarction } & \multirow[b]{2}{*}{ Pvalue } \\
\hline & & $95 \% C I$ & $\chi^{2}(1 d f)$ & \\
\hline \multirow[t]{2}{*}{$\begin{array}{l}\text { None } \\
\text { Age only } \\
\text { Age }+ \text { social class } \\
\text { Age }+ \text { risk factors } \\
\text { Age + risk factors } \\
\text { social class }\end{array}$} & $\begin{array}{l}1.84 \\
1.83 \\
1.58 \\
1 \cdot 46\end{array}$ & $\begin{array}{l}1.08 \text { to } 3.14 \\
1.07 \text { to } 3.12 \\
0.91 \text { to } 2.76 \\
0.81 \text { to } 2.64\end{array}$ & $\begin{array}{l}5 \cdot 21 \\
5 \cdot 05 \\
2 \cdot 72 \\
1 \cdot 55\end{array}$ & $\begin{array}{l}0 \cdot 02 \\
0 \cdot 02 \\
0 \cdot 10 \\
0 \cdot 21\end{array}$ \\
\hline & $1 \cdot 31$ & 0.70 to 2.43 & 0.72 & $0 \cdot 40$ \\
\hline \multirow[t]{2}{*}{$\begin{array}{l}\text { None } \\
\text { Age only } \\
\text { Age + social class } \\
\text { Age + risk factors } \\
\text { Age + risk factors } \\
\text { social class }\end{array}$} & $\begin{array}{l}1.72 \\
1.69 \\
1.39 \\
1.08\end{array}$ & $\begin{array}{l}\text { Stroke } \\
1.00 \text { to } 2.97 \\
0.98 \text { to } 2.93 \\
0.77 \text { to } 2.50 \\
0.53 \text { to } 2.20\end{array}$ & $\begin{array}{l}3.95 \\
3.68 \\
1.28 \\
0.05\end{array}$ & $\begin{array}{l}0.05 \\
0.06 \\
0 \cdot 26 \\
0 \cdot 83\end{array}$ \\
\hline & 0.96 & 0.46 to 2.02 & 0.01 & 0.92 \\
\hline
\end{tabular}

All analyses are standardised for town. ${ }^{\star}$ Risk factors adjusted for include: cigarette smoking, systolic pressure, glucose and height-standardised $\mathrm{FEV}_{1}$.

statistically significant, and no similar effect was observed for stroke.

\section{Discussion}

In this study, $H$ pylori seropositivity was associated with an increased risk both of myocardial infarction and stroke before adjustment. However, $H$ pylori seropositivity was strongly associated with adult social class and with several major risk factors for cardiovascular disease-particularly cigarette smoking, blood pressure, blood glucose, and $\mathrm{FEV}_{1}$. After adjustment for these factors, the relation between $H$ pylori and coronary heart disease was considerably weakened and the relation with stroke was effectively abolished.

The use of a case-control study nested within a cohort study has several advantages over the earlier studies. Cases are based on new coronary or stroke events, which in most cases were incident events. The assessment of cardiovascular risk factors and other potential confounders was carried out before the cardiovascular events defining the cases and was considerably more detailed than in the earlier studies. The seroprevalence rate in the control group of this study, which was higher than that in earlier population-based studies of middle aged British men, ${ }^{811}$ may be partly accounted for by the marked regional variation in seroprevalence observed in this study and partly by the earlier dates of birth of the present cohort (1919 to 1939), compared with those of the other study populations.

The size of the age-adjusted increase in risk of coronary heart disease is similar to those reported in earlier studies, ${ }^{11} 12$ when sampling error is taken into account. However, in contrast to the two previous studies, $H$ pylori seropositivity was strongly related to recognised cardiovascular risk factors (particularly cigarette smoking, blood pressure, blood glucose, and $\mathrm{FEV}_{1}$ ) to a degree which resulted in substantial confounding of the association between $H$ pylori and coronary heart disease, and almost complete confounding in the case of stroke. These associations were not observed in the earlier case-control studies, although one other small study based in a general practice suggested an association between $H$ pylori infection and risk of hypertension. ${ }^{22}$ The interpretation of the associations between
$H$ pylori infection and cardiovascular risk factors (whether causal or not) is crucial, because this will determine whether adjustment for these factors is appropriate. ${ }^{23}$ Taken together, the associations between $H$ pylori infection and cardiovascular risk factors in studies conducted to date are not sufficiently consistent to provide strong evidence of a causal relation. However, poverty in early life, a strong predictor of $H$ pylori infection, ${ }^{45}$ has been postulated as a cause of an adverse cardiovascular risk profile in adult life, ${ }^{3}$ possibly through its association with low birthweight. ${ }^{24-27}$ If this is the case, adjustment for cardiovascular risk factors in the analysis would not necessarily be appropriate.

The results of our nested case-control study suggest that future studies will need to examine the relations between $H$ pylori seropositivity and conventional cardiovascular risk factors and control rigorously for confounding where appropriate. Ideally, such studies should also include measurement of acute phase reactants including plasma fibrinogen, an independent marker of coronary risk, ${ }^{28} 29$ which may be raised in the presence of $H$ pylori infection. ${ }^{12} 30$ Intervention studies are also required to assess the effect of therapeutic eradication of $H$ pylori on cardiovascular risk factors. We thank Joanna Levy and Praful Patel for carrying out the $H$ pylori analyses. The British Regional Heart Study is a British
Heart Foundation Research Group and receives support from the Stroke Association and the Department of Health.

1 Barker DJP, Winter PD, Osmond C, Margetts B, Simmonds SJ. Weight in infancy and death from ischaemic heart disease. Lancet 1989;ii:577-80.

2 Elford J, Whincup PH, Shaper AG. Early life experience and adult cardiovascular disease. Longitudinal and caseand adult cardiovascular disease. Longitudinal a

3 Barker DJP. The fetal and infant origins of inequalities of health in Britain. $₹$ Public Health Med 1991;13:64-8.

health in Britain. f Public Health Med 1991;13:64-8.
4 Mendall MA, Goggin PM, Molineaux N, Levy J, Toosy T, Mendall MA, Goggin PM, Molineaux N, Levy J, Toosy T,
Strachan D, et al. Association between childhood living Strachan $\mathrm{D}$, et al. Association between childhood living
conditions and Helicobacter pylori seropositivity in adult conditions and Helicobacter

5 Webb PM, Knight T, Greaves S, Wilson A, Newell DG, Elder J, et al. Relation between infections with Helicobacter pylori and living conditions in childhood: evidence for person to person transmission in early life. $\mathrm{Br} \mathrm{Med} \mathcal{F}$ 1994;308:750-3.

6 Marshall BJ, Warren JR. Pylori: unidentified curved bacilli in the stomach of patients with gastritis and peptic ulceration. Lancet 1984;i:1311-4.

7 Forman D, Newell DG, Fullerton F, Yarnell JWG, Stacey $\mathrm{AR}$, Wald N, et al. Association between infection with Helicobacter pylori and risk of gastric cancer: evidence from a prospective investigation. $\mathrm{Br} M e d \mathcal{F} 1991 ; 302$ : 1302-5.

8 EUROGAST Study Group. An international association between Helicobacter pylori infection and gastric cancer. Lancet 1993;341:1359-62.

9 Langman MJS, Cooke AR. Gastric and duodenal ulcer and their associated diseases. Lancet 1976;i:680-3.

10 Sonnenburg A. Concordant occurrence of gastric and hypertensive diseases. Gastroenterology 1988;95:42-8.

1 Mendall MA, Goggin PM, Molineaux N, Levy J, Toosy T, Strachan D, et al. Relation of Helicobacter pylori infection and coronary heart disease. Br Heart $₹$ 1994;71:437-9.

12 Patel P, Mendall MA, Carrington D, Strachan DP, Leatham E, Molineaux N, et al. Association of Helicobacter pylori and Chlamydia pneumoniae infections with coronary heart disease and cardiovascular risk fac-
tors. $B r M e d ~$
1995;311:711-4.

13 Shaper AG, Pocock SJ, Walker M, Cohen NM, Wale CJ, Thomson AG. British Regional Heart Study: cardiovasThomson AG. British Regional Heart Study: cardiovas-
cular risk factors in middle-aged men in 24 towns. $\mathrm{Br}$
Med $\mathcal{F}^{1981 ; 283: 179-86}$.

14 Shaper AG, Cook DG, Walker M, MacFarlane PW. Phaper AG, Cook DG, Walker M, MacFarlane PW.
Prevalence of ischaemic heart disease in middle-aged Prevalence of ischaemic heart disease
British men. Br Heart $\mathcal{F} 1984 ; 51: 595-605$.

15 Walker M, Shaper AG. Follow-up of subjects in prospective studies based in general practice. $\Im$ $R$ Coll Gen Pract tive studies based

16 Shaper AG, Pocock SJ, Walker M, Phillips AN, Whitehead TP, MacFarlane PW. Risk factors for ischaemic heart 
disease: the prospective phase of the British Regional Heart Study. F Epidemiol Commmunity Health 1985;39: 197-209.

17 Cook DG, Shaper AG, MacFarlane PW. Using the WHO (Rose) angina questionnaire in cardiovascular epidemiological studies. Administration, definition and predictive value. Int $\mathcal{F}$ Epidemiol 1989;18:607-13.

18 Cook DG, Shaper AG. Breathlessness, lung function and risk of heart attack. Eur Heart f 1988;9:1215-22.

19 Macfarlane PW. A modified axial lead system for orthogonal lead electrocardiography. Cardiovasc Res 1969;3:510-5.

20 Thelle DS, Shaper AG, Whitehead TP, Bullock DG Ashby D, Patel I. Blood lipids in middle-aged British men. Br Heart $\mathcal{f}$ 1983;49:205-13.

21 SAS Institute. SAS Procedures Guide, Version 6. SAS Institute Inc, Cary, USA, 1990 (3rd edition).

22 Barnes RJ, Uff JS, Dent JC, Gear MWL, Wilkinson SP. Long-term follow-up of patients with gastritis associated with Helicobacter pylori infection. Brf Gen Pract 1991;41: 286-8.

23 Rothman KJ. Modern epidemiology. Boston: Little, Brown., 1986:89-97.

24 Bartley M, Power C, Blane D, Davey Smith G, Shipley M. Birth weight and later socioeconomic disadvantage: evi- dence from the 1958 British cohort study. $\mathrm{Br} \mathrm{Med} \mathcal{F}$ 1994;309:1475-9.

25 Barker DJP, Bull AR, Osmond C, Simmonds SJ. Fetal and placental size and risk of hypertension in adult life. $\mathrm{Br}$ Med F 1990;301:259-62.

26 Hales CN, Barker DJP, Clark PMS, Cox LJ, Fall C Osmond C, et al. Fetal and infant growth and impaired glucose tolerance at age 64. Br Med 7 1991;303:1019-22.

27 Barker DJP, Godfrey KM, Fall C, Osmond C, Winter PD Shaheen SO. Relation of birthweight and childhood respiratory infection to adult lung function and death from chronic obstructive airways disease. $\mathrm{Br}$ Med $\mathcal{F} 1991 ; 303$ : 671-5.

28 Ernst E. Fibrinogen as a cardiovascular risk factor-interrelationships with infections and inflammation. Eur Heart f 1993;14(suppl K):82-7.

29 Yarnell JWG, Baker IA, Sweetnam PM, Bainton D, O'Brien JR, Whitehead PJ, et al. Fibrinogen, viscosity and white cell count are major risk factors for ischaemic heart disease. Circulation 1991;83:836-44.

30 Patel P, Carrington D, Strachan DP, Leatham E, Goggin $P$ Northfield $T C$, et al. Fibrinogen: a link between chronic infection and coronary heart disease (letter). Lancet 1994;343:1634-5. 